\title{
Corrigendum
}

\section{Corrigendum to "Fuel Cells: A Real Option for Unmanned Aerial Vehicles Propulsion"}

\author{
Óscar González-Espasandín, ${ }^{1}$ Teresa J. Leo, ${ }^{2}$ and Emilio Navarro-Arévalo ${ }^{3}$ \\ ${ }^{1}$ Instituto Nacional de Técnica Aeroespacial "Esteban Terradas” (INTA), Carretera Ajalvir km.4., Torrejón de Ardoz, \\ 28850 Madrid, Spain \\ ${ }^{2}$ Departamento de Sistemas Oceánicos y Navales, ETSI Navales, Universidad Politécnica de Madrid, Avenida Arco de la Victoria 4, \\ 28040 Madrid, Spain \\ ${ }^{3}$ Departamento de Motopropulsión y Termofluidodinámica, ETSI Aeronáuticos, Universidad Politécnica de Madrid, \\ Plaza Cardenal Cisneros 3, 28040 Madrid, Spain
}

Correspondence should be addressed to Teresa J. Leo; teresa.leo.mena@upm.es

Received 26 March 2015; Accepted 16 April 2015

Copyright (C) 2015 Óscar González-Espasandín et al. This is an open access article distributed under the Creative Commons Attribution License, which permits unrestricted use, distribution, and reproduction in any medium, provided the original work is properly cited.

In "Fuel Cells: A Real Option for Unmanned Aerial Vehicles Propulsion" some unclarities were detected in several figures shown in Table 2. To clarify the table, for the Horizon Energy Systems/AEROPAK, the weight $(3.5 \mathrm{~kg})$ has been replaced only by the FC weight $(0.47 \mathrm{~kg})$; therefore, the FC power density changes from $57.14 \mathrm{~W} / \mathrm{kg}$ to $425.53 \mathrm{~W} / \mathrm{kg}$. Also, the FC power of PROTONEX/ProCore VI is changed from $800 \mathrm{~W}$ (peak power) to $280 \mathrm{~W}$ (output power), which implies FC power density of $686.27 \mathrm{~W} / \mathrm{kg}$.

We provide the updated Table 2. 
TABLE 2: Examples of PEM fuel cells for UAV applications. Specifications from manufacturers' websites and [18].

\begin{tabular}{|c|c|c|c|c|c|}
\hline Fuel type & Manufacturer/model & $\begin{array}{c}\text { FC weight } \\
(\mathrm{kg})\end{array}$ & $\begin{array}{l}\text { FC power } \\
(\mathrm{W})\end{array}$ & $\begin{array}{c}\text { FC power } \\
\text { density }(\mathrm{W} / \mathrm{kg})\end{array}$ & Application/remarks \\
\hline $\begin{array}{l}\text { Chemical } \\
\text { hydride } \\
\text { cartridge }\end{array}$ & $\begin{array}{l}\text { Horizon Energy } \\
\text { Systems/AEROPAK }\end{array}$ & 0.470 & 200 & 425.53 & $\begin{array}{l}\text { IAI Bird Eye } 650 \text { LE UAV } \\
10 \text { A-21 V nominal } 600 \mathrm{~W} \text { with } \\
\text { LiPo batteries; cartridge type I: } \\
446 \mathrm{Wh} / \mathrm{kg} \text {; type II: } 607 \mathrm{Wh} / \mathrm{kg} \\
\text { Also used in Bluebird } \\
\text { Boomerang Mini-UAV and Elbit } \\
\text { Skylark UAV }\end{array}$ \\
\hline $\begin{array}{l}\text { Sodium } \\
\text { borohydride }\end{array}$ & Protonex/UAV C-250 & 1.2 & 250 & 208.33 & $\begin{array}{l}500 \mathrm{~W} \text { peak power with batteries } \\
\text { Fuel } 833 \mathrm{Wh} / \mathrm{kg} \text { hydrated } \\
\text { Cartridge } 1.8 \mathrm{~kg}, 1.5 \mathrm{l}\end{array}$ \\
\hline $\begin{array}{l}\text { Compressed } \\
\mathrm{H}_{2}\end{array}$ & $\begin{array}{l}\text { Protonex/Spider Lion UAV } \\
\text { (NRL) }\end{array}$ & 1.77 & 95 & 53.67 & $\begin{array}{l}\text { Spider Lion Micro-UAV 2005, } \\
\text { 3-hour flight }\end{array}$ \\
\hline $\begin{array}{l}\text { Compressed } \\
\mathrm{H}_{2}\end{array}$ & $\begin{array}{l}\text { Protonex/Ion Tiger UAV } \\
\text { (NRL) }\end{array}$ & 1 & 550 & 550 & $\begin{array}{l}\text { Ion Tiger UAV; } 550 \mathrm{~W} \text { FC }(1 \mathrm{~kg}+ \\
\left.3.6 \mathrm{~kg} \text { tank } 0.5 \mathrm{~kg} \mathrm{H}_{2}\right), 26 \mathrm{~h} 1 \mathrm{~m} \\
\text { flight record in } 2009 \\
\text { Powerplant total weight } \\
\text { (including fuel and cooling) = } \\
6 \mathrm{~kg} \text {. Specific energy } 1300 \mathrm{Wh} / \mathrm{kg} \text {; } \\
26 \mathrm{~h} \text { endurance }\end{array}$ \\
\hline $\begin{array}{l}\text { Compressed } \\
\mathrm{H}_{2}\end{array}$ & EnergyOr/EO-310-XLE & 3.95 & 310 & 78.48 & $\begin{array}{l}\text { Radiant Coral Technologies } \\
\text { demonstrator UAV 1st flight } \\
\text { February 25, } 2013 \\
\text { Hybrid; the weight includes } \\
\text { auxiliary systems }\end{array}$ \\
\hline $\begin{array}{l}\text { Compressed } \\
\mathrm{H}_{2} \\
\end{array}$ & EnergyOr/EO-210-XLE & 3.65 & 250 & 68.49 & $\begin{array}{l}\text { The weight includes auxiliary } \\
\text { systems }\end{array}$ \\
\hline $\begin{array}{l}\text { Compressed } \\
\mathrm{H}_{2} \\
\end{array}$ & DLR/HyFish UAV & 3 & 1000 & 333.33 & HyFish UAV 2007, 0.5-hour flight \\
\hline $\begin{array}{l}\text { Compressed } \\
\mathrm{H}_{2}\end{array}$ & UTRC/Gen1 & 1.78 & 1200 & 674.16 & $\begin{array}{l}\text { Helicopter UAV (October 11, } \\
\text { 2009) FC (675 W/kg) Powerplant } \\
\text { (500 W/kg) Minicopter Maxi } \\
\text { Joker; } 20 \text { m flight }\end{array}$ \\
\hline $\begin{array}{l}\text { Compressed } \\
\mathrm{H}_{2}\end{array}$ & BCS/BCS500 & 6.35 & 500 & 78.74 & $\begin{array}{l}\text { Georgia Tech University UAV } \\
2006 \text { Powerplant weight } 12 \mathrm{~kg}\end{array}$ \\
\hline $\begin{array}{l}\text { Compressed } \\
\mathrm{H}_{2}\end{array}$ & $\begin{array}{l}\text { Horizon Energy } \\
\text { Systems/H-100 }\end{array}$ & 1.36 & 100 & 73.53 & $\begin{array}{l}\text { Johannesburg University Piper } \\
\text { Cub UAV }\end{array}$ \\
\hline $\begin{array}{l}\text { Sodium } \\
\text { borohydride }\end{array}$ & Protonex/ProCore VI & 0.408 & 280 & 686.27 & $\begin{array}{l}\text { AeroVironment Puma UAV } 2008 \\
\text { Endurance } 9 \mathrm{~h}\end{array}$ \\
\hline $\begin{array}{l}\text { Compressed } \\
\mathrm{H}_{2}\end{array}$ & $\begin{array}{l}\text { Horizon Fuel Cell } \\
\text { Technologies }\end{array}$ & 5 & 650 & 130 & $\begin{array}{l}\text { Pterosaur Micro-UAV } 2008 . \\
\text { Oklahoma State and California } \\
\text { State Universities } 15.5 \mathrm{~h} \\
\text { endurance; FC } 480 \mathrm{Wh} / \mathrm{kg}\end{array}$ \\
\hline Liquid $\mathrm{H}_{2}$ & $\begin{array}{c}\text { NASA/Sensor } \\
\text { Technology/AeroVironment }\end{array}$ & - & - & - & $\begin{array}{l}\text { AeroVironment Global Observer } \\
\text { (GO-1); 65,000 ft alt., 7-day } \\
\text { endurance; PL } 180 \mathrm{~kg}\end{array}$ \\
\hline
\end{tabular}



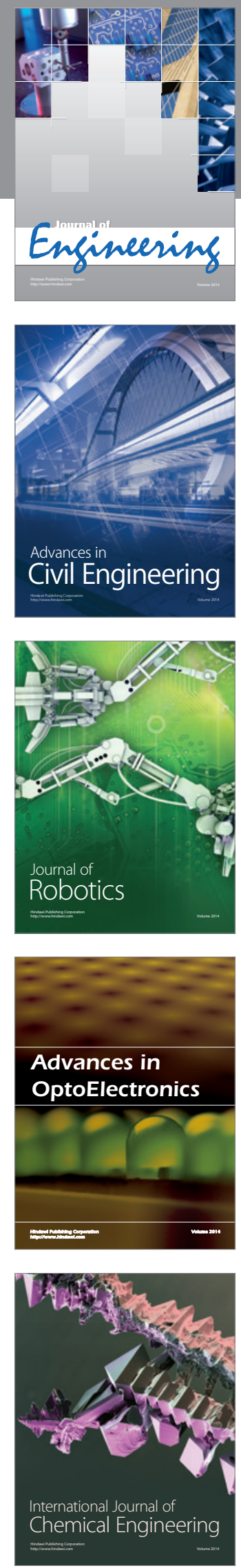

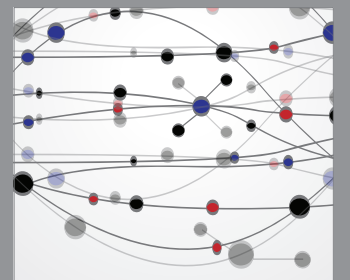

The Scientific World Journal
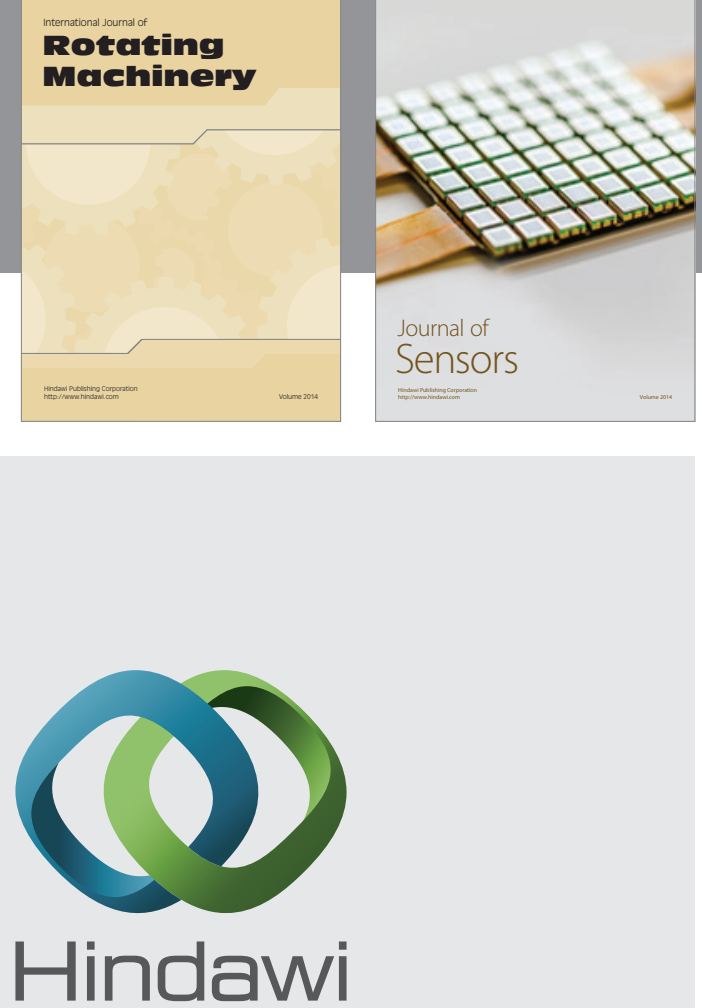

Submit your manuscripts at http://www.hindawi.com
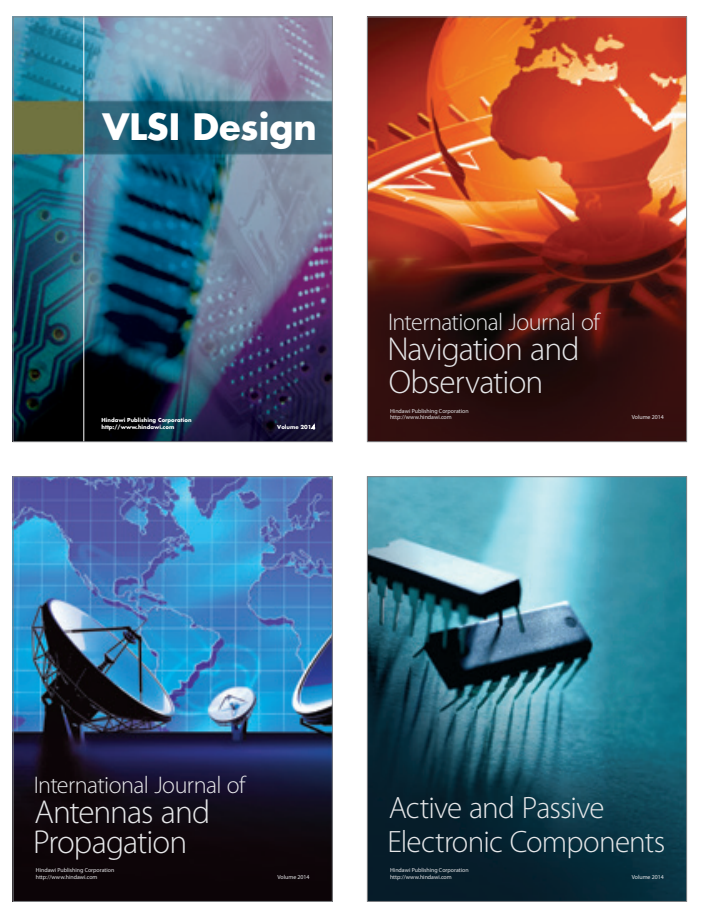
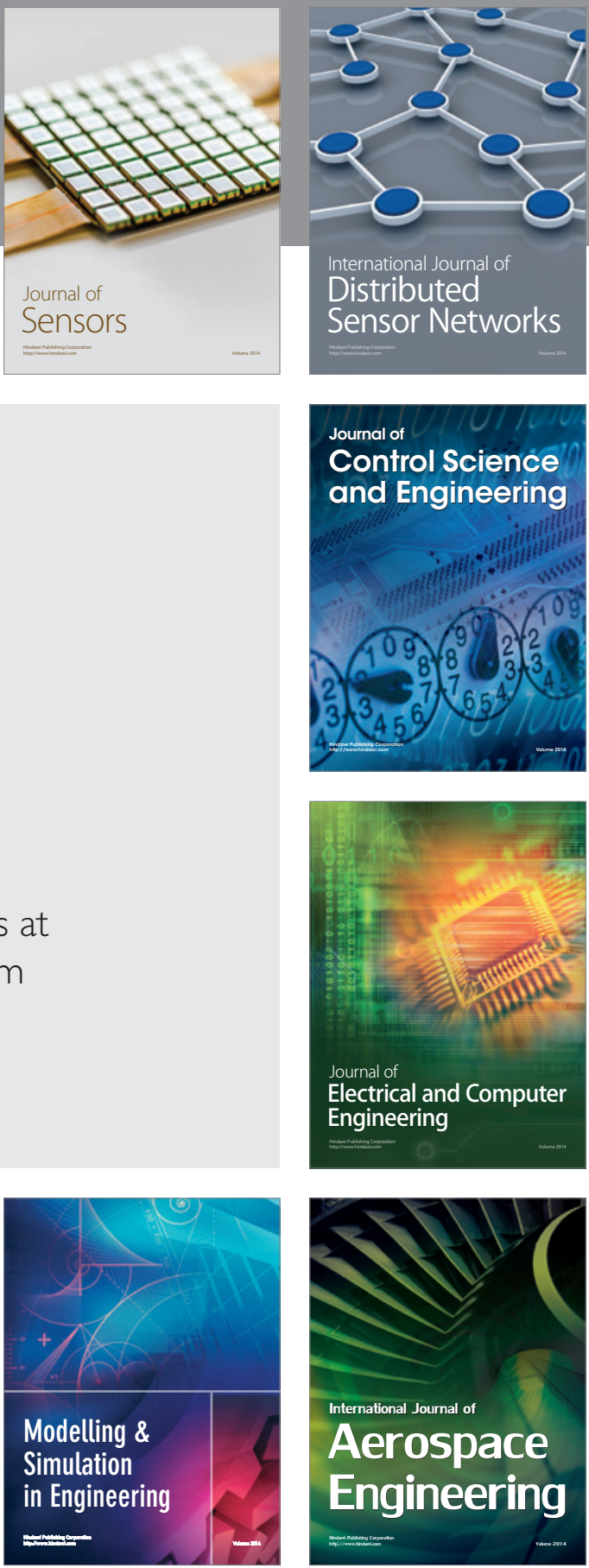

Journal of

Control Science

and Engineering
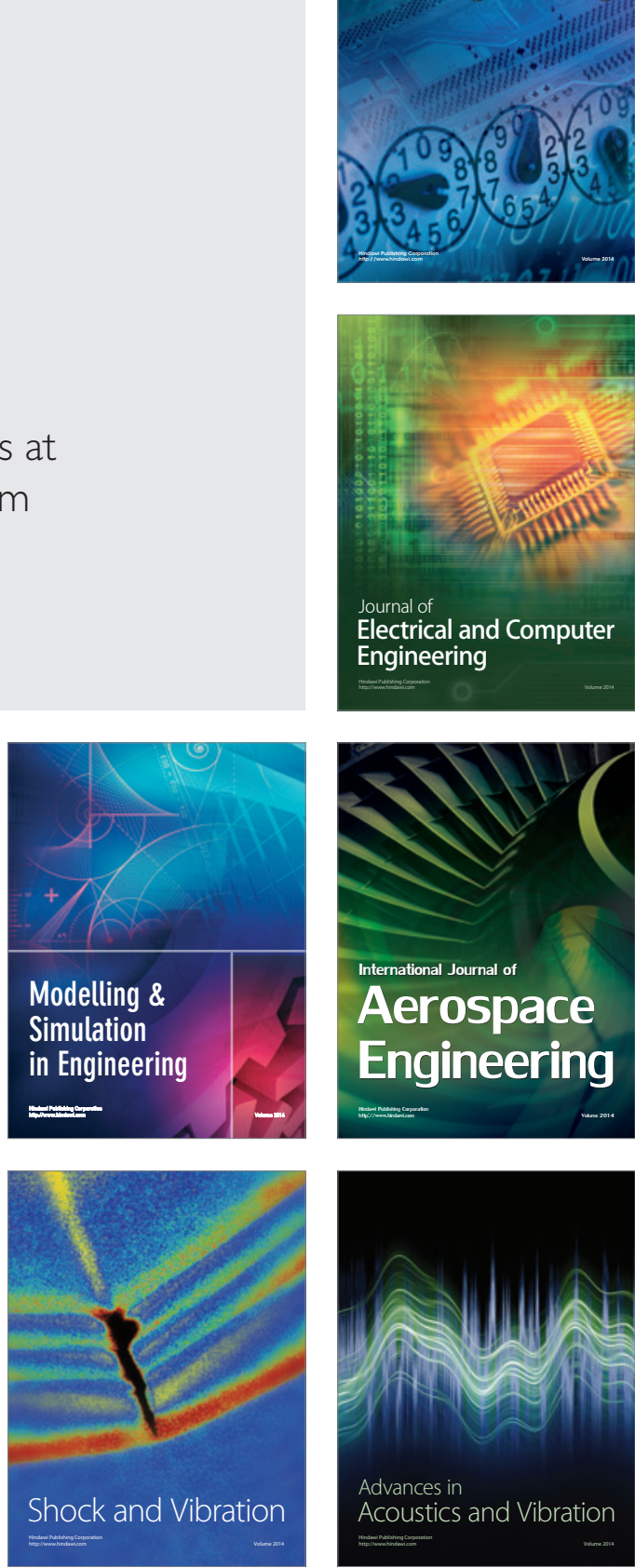